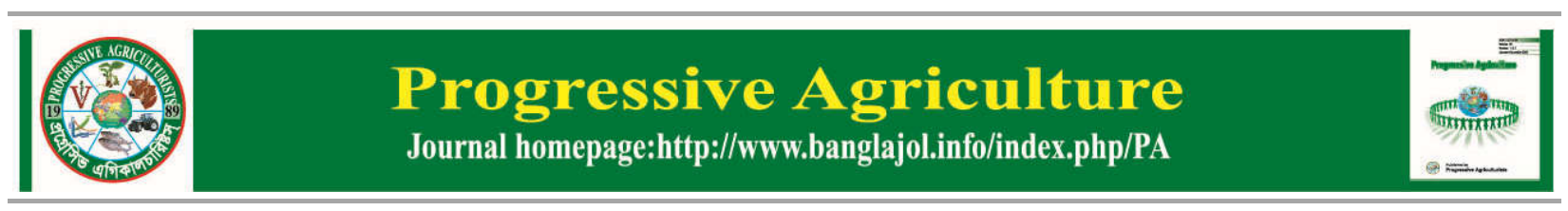

\title{
Effects of Spirulina platensis on alloxan induced diabetic rats
}

\author{
SMAK Hussaini, MI Hossain, MS Islam, K Rafiq*
}

\author{
Department of Pharmacology, Faculty of Veterinary Science, Bangladesh Agricultural University, \\ Mymensingh 2202, Bangladesh
}

\begin{abstract}
The study was undertaken to investigate the effects of Spirulina platensis on body weight, blood glucose and lipid profile on alloxan induced diabetic rats. Fifteen Long Evans male rats at six weeks of age were used for the experiment. Diabetes was induced by intraperitoneal injection of alloxan@150 mg/kg and experiment was carried out for a period of 6 weeks. Rats were divided into three groups of 5 rats each. The groups were i)healthy control, ii) diabetic control with both receiving rats' pellet as supplement, and iii) diabetic treated with oral administration of Spirulina platensis @ $400 \mathrm{mg} / \mathrm{kg}$ bwt. Results from the study showed that Spirulina platensis reduced blood glucose significantly $(P<0.01)$ and increased body weight significantly $(P<0.05)$ in contrast to diabetic control group after 6 weeks. Lipid profile analysis with Spirulina platensis @ $400 \mathrm{mg} / \mathrm{kg}$ showed that total cholesterol, plasma triglycerides, and LDL were lowered significantly compared to diabetic groups in contrast to HDL levels which were increased following the use of Spirulina platensis. Our findings showed that oral administration of Spirulina platensis could reduce the adverse effect of alloxan induced diabetes in rats. Based on this research it can be concluded that Spirulina platensis has antihyperglycemic and hypolipidimic effects in alloxan induced diabetic rats.
\end{abstract}

Key words: Spirulina platensis, antidiabetic, hypolipidemic, alloxan induced rat

Progressive Agriculturists. All rights reserved

*Corresponding Author: krafiq73@yahoo.com

\section{Introduction}

Diabetes is the most common endocrine disorder in both human and pet animals described as a heterogeneous syndrome with hyperglycemia as the hallmark. It is a major health problem in both urban and rural areas of Bangladesh (Sumon et al., 2008). Elevation of blood glucose level and reproductive malfunction are common symptoms in diabetic patients (Shukla et al., 2011). The underlying cause of diabetes is a defect in the production or action of insulin, a hormone that controls glucose, fat, and amino acid metabolism. In diabetes the body either fails to properly respond to its own insulin, does not make enough insulin, or both. This leads to glucose accumulation in the blood predisposing the individual to various complications (Ritu and Nandi M 2016).

According to the American Diabetes Association (1998), 1.6 million cases were diagnosed with diabetes from the age of 20 and above annually. The diabetic population is rapidly increasing globally, particularly in developing countries. South Asia which includes Bangladesh is a vulnerable focus. The estimated prevalence of diabetes in Bangladesh is around 4\%, which is similar to the average prevalence in many other countries (Khan, 2013). Erica Roy Khetran, country director of the Helen Keller International Bangladesh (HKIB), said, "There are currently more 
than 3.2 million people with diabetes in Bangladesh. This number is expected to rise by more than 11 million by 2030 making the country the seventh largest diabetic population in the world" (Khan, 2013).

As the prevalence of this disease increases, there is a need to look for more efficient drugs with fewer side effects. Currently available drugs may lead to obesity and hyperandrogenemia even though they bring down the glucose levels (Latha et al., 2014). Since the discovery of insulin in 1922, it has been used successfully in insulin-dependent diabetes mellitus (IDMM) (Rafiq et al., 2011).There are several drawbacks following the use of insulin, such as, insulin resistance, anorexia nervosa, brain atrophy, and fatty liver in chronic treatment (Rasineni et al., 2010).

Spirulina is the world's largest natural protein source and an important medicinal herb (Moorhead et al., 2001; Tietze 2004). Two species of this blue green algae are most commonly used as nutritional supplements, Spirulina platensis (S. Platensis) and Spirulina maxima (S.maxima) (Sixabela et al.,2011; Tefera et al.,2016). This microscopic, filamentous cyanobacterium has been claimed as a safe food for human consumption by many toxicological studies and currently belongs to the substances that are listed by the US Food and Drug Administration under the category of "Generally Recognized as Safe (GRAS)" (Sixabela et al., 2011; Chen et al., 2016).

\section{Materials and Methods}

This study was conducted in the Department of Pharmacology, Bangladesh Agricultural University, Mymensingh to evaluate the antidiabetic effects of Spirulina platensis in alloxan induced male Long Evans rats (Rattus norvegicus).

Preparation of house: The experiment room was swept and washed with tap water followed by disinfection and air drying. All utensils required for the experiment such as feeder, water bottle, micro tube, syringe, needle etc. were collected and the laboratory was properly designed with adequate ventlation.
Experimental animals and design: Fifteen adult male Long Evans rats were collected from International Centre for Diarrhoeal Diseases Research, Bangladesh (ICDDR, B) Mohakhali, Dhaka. Prior to the commencement of the experiment, all the rats were acclimatized to the new environmental condition for a period of one week. Rats were randomly divided into 3 equal groups of five in separate labeled housing. Rat pellet food and water were provided ad-libitum during the experimental period. Normal body weight and normal fasting glucose level of each animal was measured by electric balance (Camry, EK3052) and glucometer (Omron, E-OHS-BD), respectively.

Group-A (Healthy control group): The rats were administered with saline water orally and given feed and water ad-libitum. Body weights and blood glucose were recorded after one week of acclimatization and at same intervals with other groups.

Group-B (Diabetic control group): After acclimatization, body weights and blood glucose level were measured after 18 hours of starvation. Then alloxan monohydrate was injected at a dose rate of 150 $\mathrm{mg} / \mathrm{kg}$ intraperitoneally to each rat to induce diabetes (Meenakshi et al., 2010). The rats were fed normal diet and given water ad-libitum from day 1-14. On $14^{\text {th }}$ day blood glucose levels and the body weights were again measured to ensure diabetic condition. All the rats from this group were kept for 6 weeks without any treatment but body weights and blood glucose levels were recorded weekly.

Group C (Diabetic+Spirulina): Blood glucose level and body weight were measured on $15^{\text {th }}$ day of alloxan monohydrate injection to confirm diabetes. After that Spirulina platensis was fed at a dose rate of $400 \mathrm{mg} / \mathrm{kg}$ body wt. for 6 weeks. During treatment with Spirulina platensis body weights and blood glucose levels were recorded weekly for 6 weeks.

Induction of diabetes in rats: The animals were fasted for 16-18 hours with free access to water prior to the induction of diabetes with alloxan monohydrate dissolved in $0.9 \% \mathrm{v} / \mathrm{v}$ cold normal saline solution at a 
dose of $150 \mathrm{mg} / \mathrm{kg}$ body weight. Alloxan is capable of producing fatal hypoglycemia as a result of massive pancreatic insulin release. The rats were then kept for 24 hours on $5 \%$ glucose solution bottles in their cages to prevent hypoglycemia. Established diabetes was assessed 72 hours after alloxan injection. Spirulina platensis was collected from Bangladesh Council of Scientific and Industrial Research (BCSIR), Dhaka. It was preserved at room temperature and was administered at a dose rate of $400 \mathrm{mg} / \mathrm{kg}$ bwt orally for 6 weeks to group C.

Determination of blood glucose: Blood samples were collected from tail vein at day 0 (Pre-treatment) and weeks 2 and 6 (during treatment) for estimation of blood glucose level. Blood glucose level was estimated by Omron advantage blood glucose system (strip method). Body weights were taken on day 0 (pretreatment), 2 and 6 weeks (during treatment).

Collection of blood for lipid profile: On the $6^{\text {th }}$ week of experiment, the mice were anesthetized under sodium pentobarbital $(65 \mathrm{mg} / \mathrm{kg}$ intraperitoneally) anesthesia and blood samples were collected by sacrificing the mice. The abdominal cavities and thoracic cavity were opened surgically and then blood was collected directly from the heart with the sterile syringe and needle. About $1 \mathrm{~mL}$ of blood from the syringe was taken in the test tube containing anticoagulant $3.8 \%$ Sodium citrate solution) for hematological studies. Plasma was then separated by centrifugation at $4500 \mathrm{rpm}$ for 10 minutes and finally stored at $-20^{\circ} \mathrm{C}$ temperature for further analysis.

Measurement of lipid profile: Plasma total cholesterol (TC), high density lipoproteins (HDL), low density lipoproteins (LDL) and triglycerides (TG) were quantified spectrophotometrically by the addition of reagent (Linear Chemicals, S.L., Barcelona, Spain). The absorbance was determined at $550 \mathrm{~nm}$. The value of TC present in plasma was expressed in $\mathrm{mg} / \mathrm{dL}$. Plasma TG level was measured by using a kit (Linear Chemicals, S.L., Barcelona, Spain). The absorbance was measured at $500 \mathrm{~nm}$. The value was expressed in $\mathrm{mg} / \mathrm{dL}$.

Statistical analysis: The obtained data were expressed as mean \pm standard deviation. The differences among the groups of animals were compared by applying oneway ANOVA followed by Bonferonni tests, DUNCUN test and T-test. Statistical significance was set at $\mathrm{P}<$ 0.01 and $\mathrm{P}<0.05$ and it is considered significant in relation to control and standard. All statistical analysis were done using SPSS software version 20 (SPSS INC. Chicago, IL, USA).

\section{Results}

Effect of Spirulina platensis on body weight in alloxan induced diabetic rats: The effects of Spirulina platensis on body weights of alloxan induced diabetic rats were shown in Figure 1.
Healthy control vs Diabetic control **
Diabetic control vs Diabetic + Spirulina *
Diabetic+Spirulina vs Healthy control

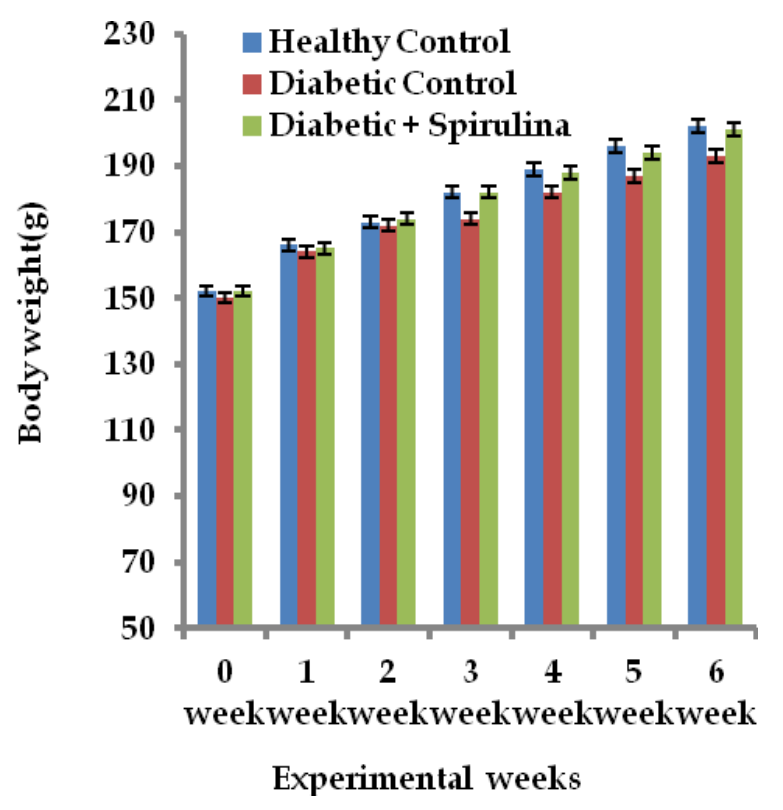

Figure 1. Effect of Spirulina platensis on body weight in alloxan induced diabetic rats. 
Weekly body weights were taken for 6 treatment weeks. The average body weights of Group-A (Healthy control) were $152 \pm 5.15 \mathrm{~g}$ and $202 \pm 1.22 \mathrm{~g}$ at 0 and 6 weeks, respectively. On the other hand, Group-B (Diabetic control) showed $150 \pm 8.94 \mathrm{~g}$ and $193 \pm 3.15 \mathrm{~g}$ respectively. Within the 6week study period Group-C (Spirulina platensis @ $400 \mathrm{mg} / \mathrm{kg}$ bwt) showed $152 \pm 5.15 \mathrm{~g}$ and $201 \pm 3.15 \mathrm{~g}$ body weight respectively. These indicated that body weight decreased significantly $(P<0.01)$ in diabetic animals compared to healthy ones. Spirulina platensis treated group improved the body weight loss in diabetic animals. In diabetic control group (Group-B, $\mathrm{n}=5$ ), the percentage of body weight loss was $4.45 \%$. On the contrary, the percent increase in body weight gain over 6 weeks in Group-C ( $\mathrm{n}=5)$, following oral administration of Spirulina platensis was $4.14 \%$. The present data suggested that even at a dose rate of $400 \mathrm{mg} / \mathrm{kg}$, Spirulina has significant effect on body weight of diabetic control group compared to healthy control group.

Effect of Spirulina platensis on blood glucose in alloxan induced diabetic rats: The effects of Spirulina platensis on rats blood glucose levels are presented in Figure 2. The results indicated that, pre-treatment with alloxan (@ 150mg/kg) induced hyperglycemia in Group-B and C but was reduced by treatment with Spirulina platensis@ @ $400 \mathrm{mg} / \mathrm{kg}$. Average fasting blood glucose level during the six weeks study period showed Group-A (Healthy control) had $4.2 \pm 0.12 \mathrm{mmol} / \mathrm{L}$ at week 0 to $4.68 \pm 0.11 \mathrm{mmol} / \mathrm{L}$ at week 6. On the other hand, in Group-B (Diabetic control), the average blood glucose level at week 0 was $4.22 \pm 0.26 \mathrm{mmol} / \mathrm{L}$ and by week 1 it was increased to $9.32 \pm 0.36 \mathrm{mmol} / \mathrm{L}$, this value further increased to $19.42 \pm 0.32 \mathrm{mmol} / \mathrm{L}$ by week 6 . The blood glucose level of Group-C at week 0 was $4.26 \pm 0.40 \mathrm{mmol} / \mathrm{L}$ and by 6th week it became $8.72 .97 \pm 0.53 \mathrm{mmol} / \mathrm{L}$. This data showed that the initial hyperglycemia following alloxan injection in week 1 was decreased by Spirulina platensis@ 400 mg/kg bwt.

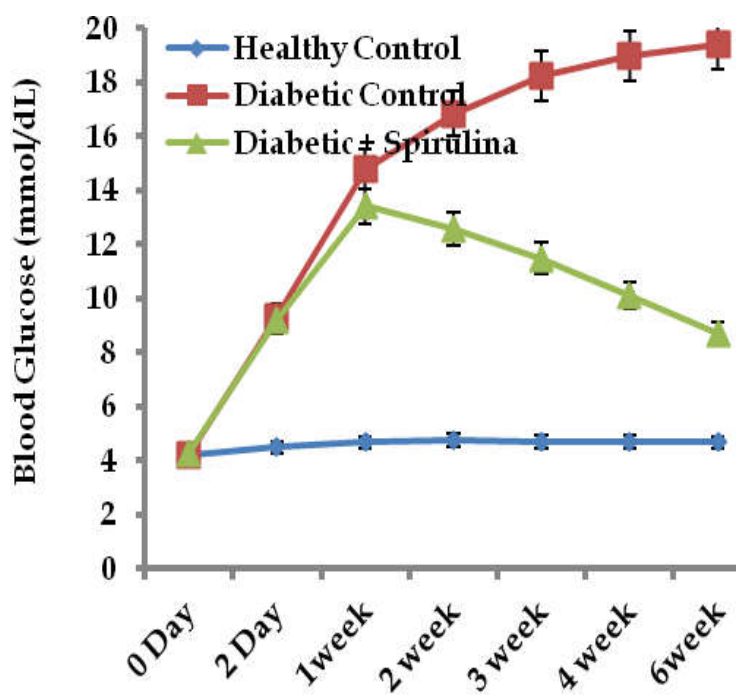

Experimental weeks

Figure 2. Effect of Spirulina platensis on blood glucose level in alloxan induced diabetic rats $(\mathrm{n}=5)$.

Effect of Spirulina platensis on plasma total cholesterol (TC) in alloxan induced diabetic rats: After 6 weeks of treatment, average total cholesterol (TC) level of Group-A (Healthy control) was $98 \pm 0.71$ $\mathrm{mg} / \mathrm{dL}$. Group B and group C were 136.4 \pm 3.4 and $115.6 \pm 10 \mathrm{mg} / \mathrm{dL}$, respectively (Figure 3 ).

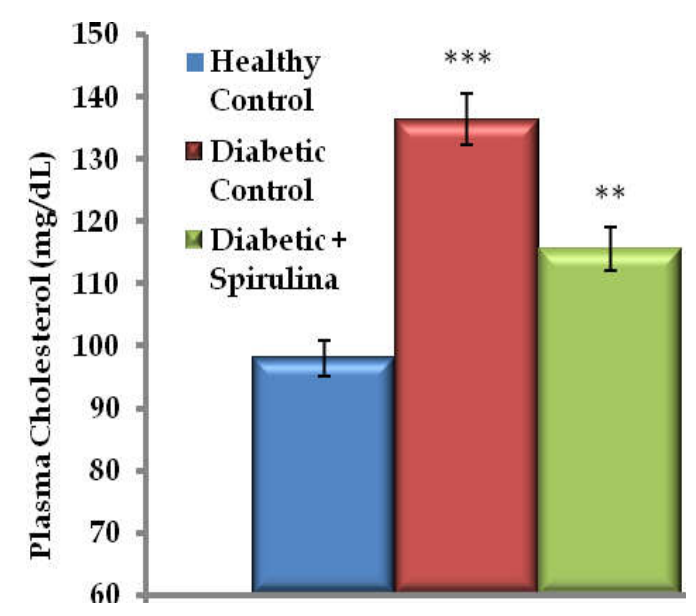

Figure 3. Effect of Spirulina platensis on plasma total cholesterol (TC) in alloxan induced diabetic rats. 
These findings were found statistically significant $(\mathrm{P}<0.05)$. These data from the study suggested that herbal formulation of Spirulina platensis @ 400mg/kg have significant effect on total cholesterol level in alloxan induced diabetic rats.

\section{Effect of Spirulina platensis on HDL in alloxan} induced diabetic rats: Average HDL level of Group-A was $24.6 \pm 0.51 \mathrm{mg} / \mathrm{dL}$ after the six week study period (Figure 4). Group-B was reduced to $19.2 \pm 0.37 \mathrm{mg} / \mathrm{dL}$. After 6 weeks of treatment, the HDL level of Group-C (Spirulina platensis $400 \mathrm{mg} / \mathrm{kg}$ bwt) increased the HDL level to $21.6 \pm 1.78 \mathrm{mg} / \mathrm{dL}$.

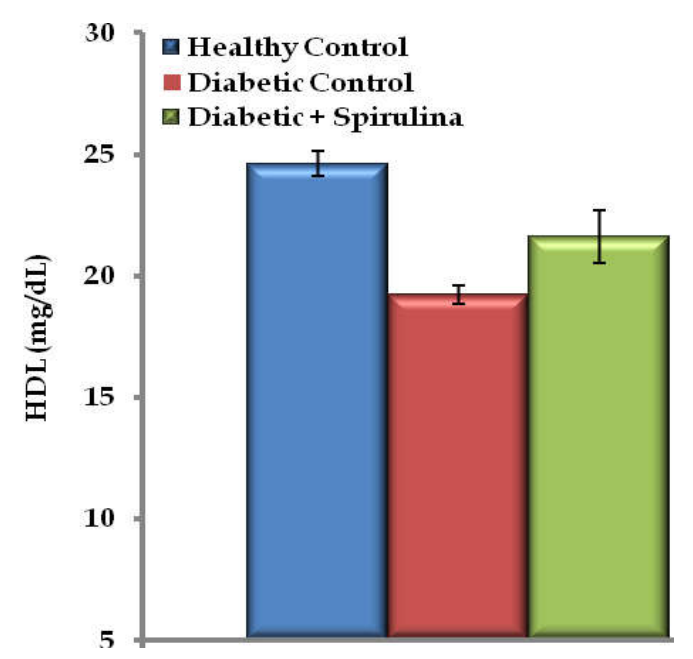

Figure 4. Effect of Spirulina platensis on HDL $(\mathrm{mg} / \mathrm{dL})$ in alloxan induced diabetic rats $(\mathrm{n}=5)$.

Effect of Spirulina platensis on LDL in alloxan induced diabetic rats: The average LDL levels of Group-A rats were $51.4 \pm 1.0 \mathrm{mg} / \mathrm{dL}$ (Figure 5). GroupB LDL levels were increased to $66.8 \pm 2.4 \mathrm{mg} / \mathrm{dL}$ after alloxan induction.These findings were statistically significant $(P<0.05)$. The LDL level of Group-C (treatment with Spirulina platensis $400 \mathrm{mg} / \mathrm{kg}$ bwt) was lowered to $58.4 \pm 1.69 \mathrm{mg} / \mathrm{dL}$ respectively $(P<0.05)$.

Effect of Spirulina platensis on Triglyceride (TG) in alloxan induced diabetic rats: Average triglyceride (TG) levels of Group-A (Healthy control) were
151.6 $\pm 2.6 \mathrm{mg} / \mathrm{dL}$ (Figure 6). Group-B (diabetic control) had elevated levels of TG significantly $(P<0.001)$ After 6 weeks of treatment, the triglyceride level of Group-C (treatment with Spirulina platensis $400 \mathrm{mg} / \mathrm{kg}$ body weight) was reduced to $184.4 \pm 3.8$ $\mathrm{mg} / \mathrm{dL}$ whereas significantly elevated levels were found in group B.

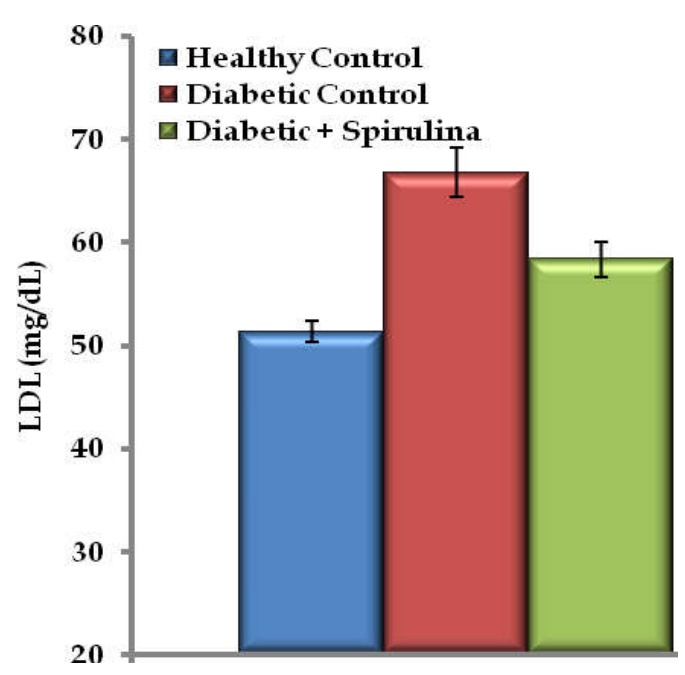

Figure 5. Effect of Spirulina platensis on LDL $(\mathrm{mg} / \mathrm{dL})$ in alloxan induced diabetic rats $(\mathrm{n}=5)$.

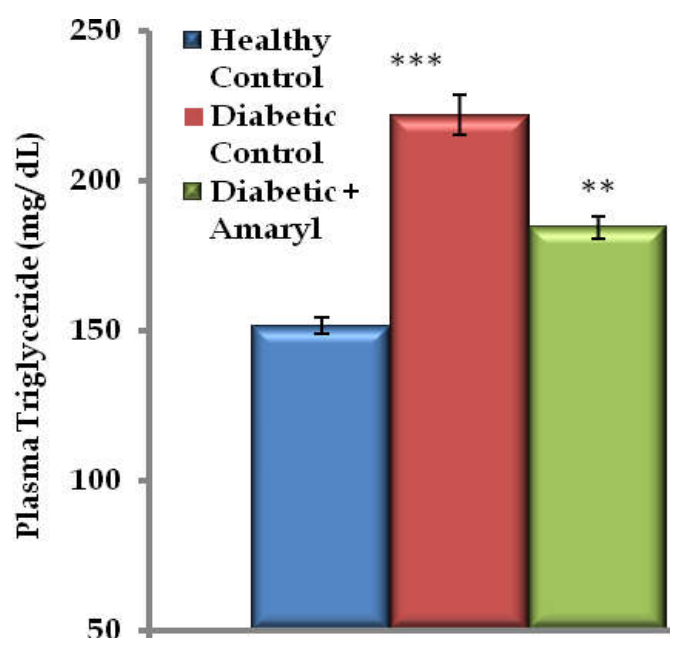

Figure 6. Effect of Spirulina platensis on TG $(\mathrm{mg} / \mathrm{dL})$ in alloxan induced diabetic rats $(\mathrm{n}=5)$. 


\section{Discussion}

Results of this experiment indicate that Spirulina platensis has a significant effect on glucose level and lipid profiles. The body weights before the treatment were similar between the groups. Alloxan induced diabetes showed severe loss in body weight, which has also been reported by other researchers (Erejuwa et al., 2010) Previous reports showed that protein synthesis is decreased in all tissues due to decreased production of adenosine triphosphate and absolute or relative deficiency of insulin. Body weight was elevated by the treatment with Spirulina platensis (@400 mg/kg bwt) for 3 weeks. Administration of Spirulina platensis in alloxan induced diabetic rats showed a significant $(P<0.05)$ improvement in body weight loss when compared to diabetic control rats. Following diabetic induction there was significant change in body weight $(P<0.05)$ between healthy control and diabetic control rats. A similar result was calculated by Zafar and Naqvi (2010) that significant decrease was observed in the final values of the body weight when diabetic control was compared with normal control $\operatorname{rats}(P<0.001)$. Alloxan induced diabetic animal model of type-1 diabetes and hyperlipidemia is a good model to study diabetes (Soon and Tan 2002). Insulin deficiency will lead to decreased activity of lipoprotein lipase and increased mobilisation of free fatty acids from peripheral fat depots.

After alloxan injection, persistent hyperglycemia was recorded after 7 days which was also observed by Eizirik et al. (1994) where the persistent hyperglycemia as early as in 72 hours followed by clinical features of polyuria, polydipsia, and polyphagia was found after 24 hours in this investigation. Administration of Spirulina platensis in alloxan induced diabetic rats showed a significant $(P<0.01)$ improvement in blood glucose level when compared to diabetic control rats.

The basal total cholesterol level before this treatment was similar between the groups. Alloxan induced diabetic rats showed elevated total cholesterol level
$(P<0.001)$ compared to control group, this result is in agreement with Bopanna et al. (1997). Akcilar et al. (2016) found that streptozocin induced diabetic rats exhibit a high plasma cholesterol a,nd triglyceride level (Akcilar et al., 2016). The levels of glucose, cholesterol, triglycerides was found to be significantly increased in alloxan-induced diabetic group when compared to normal control group (Meenakshi et al., 2010).

Following the administration of Spirulina platensis (400 $\mathrm{mg} / \mathrm{kg}$ ) the plasma total cholesterol level was reduced and it prevented the further increase in cholesterol level of diabetic animals. This result is partially supported by the findings of Park and Cha (2010), as they found that total cholesterol concentrations in serum were significantly higher in the high fat diet group than in the Spirulina treated group.

Alloxan lowered the HDL-cholesterol levels in all groups which was elevated by treating one group with Spirulina platensis for 6 weeks. Sen et al., (2011) found that treatment with Spirulina platensis significantly increased serum HDL level and decreased elevated LDL level when compare to diabetic control. Sen et al., (2011) also exposed the LDL lowering potential of Spirulina platensis at a level of $25.7 \%$ compairing to diabetic control. Lakshmia et al., (2014) studied the LDL lowering potential of Spirulina platensis to a significant level $(P<0.01)$ in contrast to cholesterol treated animal.

The basal plasma TG before this treatment was similar between the groups. Alloxan induced elevated plasma triglyceride level which was reduced by treatment with Spirulina platensis treatment for 6 weeks. This result partially matches with the evaluation from Sen et al., (2011); describing that, elevated serum TG level was decreased in extract and Sprulina treated group. Hypolipidemic activity may be due to the presence of phenolic compounds leading to increased lipoprotein lipases in the muscles and decreased activity in the adipose tissues, thus indicating that plasma triglycerides are utilized for energy production by the 
muscle and not for energy storage by the adipose tissue (Khan et al., 2011). Nugroho et al., (2014) estimated that Spirulina has significant lowering effect on triglyceride levels in high fructose fed diabetic rats in contrast to normal rats. Lakshmia et al. (2014) also studied on lipid lowering potential of triglyceride and found significant variation $(P<0.01)$ comparing to cholesterol treated animals.

\section{Conclusion}

It may be concluded that the Spirulina platensis has hypoglycemic and hypolidemic effects on alloxan induced diabetic rats. It may be stated that the Spirulina platensis may provide a new therapeutic avenue against diabetes and diabetes-related complications because of its availability, cheap rate and effectiveness. A detailed study of the mechanism of action, side effects, and contraindication of this newly derived herbal medicine is recommended.

\section{References}

Akcilar R, Kocak FE, Simsek H, Akcilar A, Bayat Z, Ece E (2016). Antidiabetic and hypolipidemic effects of adropinin streoptozotocin-induced type 2 diabetic rats. Annals of Internal Medicine 117: 100-105.

ADA (American Diabetes Association) (1998). Economic consequences of diabetes mellitus in the U.S. in 1997. Diabetes Care 21: 296-309.

Bopanna KN, Kannan J, Sushma G, Balaraman R, Rathod SP (1997). Antidiabetic and antihyperlipaemic effects of neem seed kernel powder on alloxan diabetic rabbits. Indian Journal of Pharmacology 29: 162-167.

Chen YH, Chang GK, Kuo SM, Huang SY, Hu IC, Lo YL, Shih SR (2016). Well-tolerated Spirulina extract inhibits influenza virus replication and reduces virus-induced mortality. Scientific Reports, doi:10.1038/srep24253.

Eizirik DL, Pipeleers DG, Ling Z, Welsh N, Hellerstrom C, Andersson A (1994). Major species differences between humans and rodents in the susceptibility to pancreatic beta-cell injury. Proceedings of the National Academy of Sciences 91: 9253-9256.

Erejuwa OO, Sulaiman SA, Wahab MS, Salam SK, Salleh MS, Gurtu S (2010). Antioxidant protective effect of glibenclamide and metformin in combination with honey in pancreas of streptozotocin-induced diabetic rats. International Journal of Molecular Sciences 11: 2056-2066.

Khan S, Kabir H, Jalees F, Asif M, Naquvi KJ (2011). Antihyperlipidemic potential of fruits of Tribulus terterestris. International Journal of Biomedical Research 2: 98-101.

Khan AR (2013). 3.2 million people in Bangladesh suffer from diabetes. The Daily Star, October 13.

Khan M, Shobha JC, Mohan IK, Naidu MU, Sundaram C, Singh S, Kuppusamy P, Kutala VK (2005). Protective effect of Spirulina against doxorubicin-induced cardiotoxicity. Phytotherapy Research 19: 1030-1037.

Lakshmia V, Srivastav S, Khanna AK, Mahdi AA, Agarwal SK (2014). Lipid lowering potential of Andrographis paniculata (Nees). The Journal of Phytopharmacology 3: 124-129.

Latha S, Rajaram K, Kumar SP (2014). Hepatoprotective and antidiabetic effect of methanol extract of caralluma. International Journal of Pharmacy and Pharmaceutical Sciences, 6: 0-3.

Meenakshi P, Bhuvaneshwari RR, Muthaiyan AT, Lakshmanan G, Dugganaboyana CJ, Muthedath JG, Velliyur K (2010). Antidiabetic activity of ethanolic extract of Zaleya decandra in alloxaninduced diabetic rats. Applied Biochemistry and Biotechnology, 162: 1153-9.

Moorhead K, Capelli B, Cysewski GR (2001). Spirulina: Nature's superfood. $1^{\text {st }}$ ed. KailuaKona: Cyaotech corporation.

Nugroho AE, Rais IR, Setiawan I, Pratiwi PY, Hadibarata T, Tegar M, Pramono S (2014). Pancreatic effect of and rographolide isolated 
from Andrographis paniculata (Burm. f.) Nees. Pakistan Journal of Biolical Sciences 17: 22-31.

Park JE, Cha YS (2010). Stevia rebaudiana Bertoni extract supplementation improves lipid and carnitine profiles in C57BL/6J mice fed a high-fat diet. Journal of the Science of Food and agriculture 90: 1099-1105.

Rafiq K, Shamshad JS, Sufiun MA, Mostofa M, Alam A, and Barman BC (2011). Comparative efficacy of stevia leaf (Stevia rebaudiana bertoni), methi seeds (Trigonella foenum-graecum) and glimepride in streptozotocin induced rats. International Journal of Phytopharmacology 2: 9-14.

Rasineni K, Bellamkonda R, Singareddy SR, Desireddy S (2010). Antihyperglycemic activity of Catharanthus roseus leaf powder in streptozotocin-induced diabetic rats. Pharmacognosy Research 2: 195-201.

Ritu M, Nandini J (2016). Nutritional composition of Stevia rebaudiana a sweet herb and its hypoglycaemic and hypolipidaemic effect on patients with non-insulin dependent diabetes mellitus. Journal of the Science of Food and Agriculture 10: 1-13.

Sen S, Chakraborty R, De B, Mazumder J (2011). Synergistic activity of Tribulusterrestri sand Annonasquamosa extracts against alloxan induced diabetes and hyperlipidemia in rats. pharma Science Monitor 43: 976-980.
Shukla S, Mehta A, Mehta P, Bajpai VK (2011). Evaluation of comparative antidiabetic effects of ethanolic extracts of Caesalpinia bouncucella and Stevia rebaudiana in normal and alloxan- induced experimental rats. Romanian Biotechnological Letters 16: 6187-6199.

Sixabela PSS, Chivandi E, Badenhorst M, Erlwanger KH (2011). The effects of dietary supplementation with Spirulina platensis in growing rats. Asian Journal of Animal and Veterinary Advances, doi:10.3923/ajava.

Soon YY, Tan BK (2002). Evaluation of the hypoglycemic and anti-oxidant activities of Morindaofficinalis in streptozotocin-induced diabetic rats. Singapore Medical Journal 43: 7785.

Sumon MH, Mostofa M, Jahan MS, Kayesh MEH, Haque MA (2008). Comparative efficacy of powdered form of stevia. Journal of Veterinary Medicine 6: 211-215.

Tefera G, Hailu D, Tsegaye Z (2016). Importance of arthrospira (Spirulina) in sustainable development. International Journal of Current Trend in Pharmacobiology and Medical Sciences 1: 60-68.

Tietze HW (2004). Micro Food Macro Blessing. $4^{\text {th }}$ ed. India (New delhi): Jain Publishers; p.7-48.

Zafar M, Naqvi S (2010). Effects of STZ-induced diabetes on the relative weights of kidney, liver and pancreas in albino rats: a comparative study. Internatinal Journal Morphology 28: 135-142. 